\title{
The impact of mechanical cervical dilatation during elective cesarean section on postpartum scar integrity: a randomized double-blind clinical trial
}

This article was published in the following Dove Medical Press journal: International Journal of Women's Health

\author{
Ayman Shehata Dawood' \\ Adel Elgergawy' \\ Ahmed Elhalwagy' \\ Walid M Ataallah' \\ Shereen B Elbohoty' \\ Shereef L Elshwaikh' \\ Amal A Elsokary' \\ Ahmed M Elkhyat' \\ Amr T Elbadry ${ }^{2}$ \\ Ahmed M Abbas ${ }^{3}$ \\ 'Department of Obstetrics \& \\ Gynecology, Faculty of Medicine, \\ Tanta University, Tanta, Egypt; \\ ${ }^{2}$ Department of Radiology, Faculty \\ of Medicine, Tanta University, Tanta, \\ Egypt; ${ }^{3}$ Department of Obstetrics \& \\ Gynecology, Faculty of Medicine, \\ Assiut University, Assiut, Egypt
}

Objective: The current study aimed to evaluate the impact of mechanical cervical dilatation during elective cesarean section (CS) on postpartum scar integrity at 6 months post operation. Methods: A randomized double-blind clinical trial (UMIN000027946) was conducted at a tertiary university hospital in the period between July 1, 2017 and April 30, 2018. The study included pregnant women with a singleton fetus at term $\geq 37$ weeks of gestation scheduled for elective CS. Eligible participants were allocated either to the study group (women with intraoperative cervical dilatation) or the control group (women with no intraoperative cervical dilatation). The patients were followed up at 6 months after CS by 3D ultrasonography to check for the scar integrity and quality. The primary outcome was the difference in sonographic parameters of the scar integrity between the two groups.

Results: Four hundred twenty two women were approached to participate in the study. There was no statistically significant difference regarding the baseline characteristics of both the groups. Scar width and depth were significantly higher in the cervical dilatation group $(P=0.002$ and 0.001 , respectively). Fewer cases with scar defects (niche) were found in the cervical dilatation group than in the control group $(5.03 \%$ vs $11.04 \%$, respectively, $P=0.048)$. There was no significant difference regarding the rate of wound infection or endometritis in both the groups ( $P=0.717$ and 0.227 , respectively). The incidence of febrile morbidity was higher in the no cervical dilatation group $(10.5 \%)$ compared to $(5.0 \%)$ the cervical dilatation group $(P=0.045)$. Conclusion: Cervical dilatation during elective CS is associated with thick scars with low incidence of scar defects.

Keywords: cesarean section, cervical dilatation, cesarean scar defect, scar integrity

\section{Introduction}

Cesarean section (CS) is the most commonly performed surgery worldwide with a global rise of CS rate across different countries. In Egypt, the rate of CS is about $52 \%$ of all deliveries according to the latest reports. ${ }^{1} \mathrm{CS}$ is not a complication-free operation but linked to some short-term and long-term complications such as infection, bleeding, trauma to adjacent organs, peripartum hysterectomy, and anesthetic problems. $^{2}$ A lot of modifications in the surgical steps were introduced to minimize these perioperative complications. ${ }^{3}$

One of the assessed procedures during CS was mechanical dilatation of the cervix in elective cases. ${ }^{4,5}$ In 2011, a Cochrane systematic review had assessed the effects of mechanical dilatation of the cervix on postoperative morbidity and specified postpartum hemorrhage (PPH) as primary outcome measure. ${ }^{6}$ They concluded that cervical dilatation had not significantly improved the postpartum outcomes and recommend further
Correspondence: Ahmed M Abbas Gynecology, Faculty of Medicine, Assiut University, Al-Azhar street, Assiut, Egypt

Tel +20882414616

Fax +20889202503

Emailbmr90@hotmail.com
International Journal of Women's Health 2019:1। 23-29

(c) (i) (2) ๑) 2019 Dawood et al. This work is published and licensed by Dove Medical Press Limited. The full terms of this license are avalable at https://www.dovepress.com/terms.php

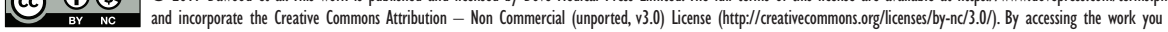
hereby accept the Terms. Non-commercial uses of the work are permitted without any further permission from Dove Medical Press Limited, provided the work is properly attributed. For permision for commercial use of this work, please see paragraphs 4.2 and 5 of our Terms (https://www.dovepress. com/terms.php). 
studies for evaluating its effect on reducing the postoperative morbidity. $^{7}$

Evaluation of CS scar integrity before next pregnancy became feasible due to improvements in imaging modalities that have facilitated the evaluation of CS scars. ${ }^{7} \mathrm{CS}$ scar defects appear as a wedge-shaped cystic or hypoechoic distortion in the scar in the nonpregnant uterus. ${ }^{8}$ Hysterosalpingography was the first modality that described the CS scar; ${ }^{9}$ then trans-abdominal (TAS) and transvaginal (TVS) ultrasound were used for the evaluation of the scar. ${ }^{10,11}$ Nowadays, three-dimensional (3D) TAS and TVS were also incorporated in the evaluation of the lower uterine segment (LUS) and scar integrity especially during pregnancy. ${ }^{12,13}$

Therefore, the current study was designed to evaluate the impact of mechanical cervical dilatation during elective CS on postpartum infectious morbidity and the scar integrity at 6 months post operation. To our knowledge, this is the first study reported in the literature to evaluate the scar integrity in nonpregnant women after mechanical cervical dilatation during elective CS.

\section{Materials and methods}

\section{Study type, setting, and duration}

The current study was a randomized double-blind clinical trial registered in UMIN-CTR (UMIN000027946) conducted at a tertiary university hospital in the period between July 1, 2017 and April 30, 2018. This study was approved by the local ethics committee of Tanta University with the code of $31677 / 6 / 17$. The study was conducted in accordance with the Declaration of Helsinki, and all participants signed a written informed consent before inclusion in the study.

\section{Study participants}

All pregnant women scheduled for elective CS under spinal anesthesia were invited to participate in the study. We included pregnant women with a singleton fetus at term $\geq 37$ weeks of gestation, with American Society of Anesthesiology physical status I or II. We excluded patients with multiple gestation, placenta previa, premature rupture of membranes, and chorioamnionitis. In addition, those with pre-eclampsia, diabetes mellitus, current or previous history of heart disease, liver, renal disorders, or known coagulopathy were excluded from the study. The recruited women were assessed preoperatively through history taking with regard to age, parity, gestational age, and body mass index measurement.

\section{Sample size calculation}

The average number of total deliveries at Tanta University hospitals was determined to be 3,500 per year. ${ }^{14}$ Postulating that cervical dilatation $\left(\mathrm{H}_{0}\right)$ yields better postoperative outcomes and correlated to good quality scars. Using $95 \%$ confidence level, $80 \%$ power, and $50 \%$ to calculate the appropriate sample size, 346 women were estimated to be included in the study. The enrolled patients were higher than this sample size owing to loss of large numbers in follow-up periods (Epi-info: Centers for Disease Control and Prevention, Atlanta, GA, USA).

\section{Randomization}

A statistician prepared a computer-generated random table and placed the group allocation in serially numbered closed opaque envelopes in a 1:1 ratio. The envelopes were opened only by the obstetrician just before CS. Patients were allocated to either study group (cervical dilatation) or control group (no cervical dilatation). Allocation was never changed after opening the envelopes. All patients were blinded to the allocation to avoid bias.

\section{Intervention}

Eligible participants were allocated to one of the two groups: Study group (women with intraoperative cervical dilatation) and control group (women with no intraoperative cervical dilatation). Cervical dilatation was carried out by inserting Hegar's dilator no. 6 into the cervical canal after removal of the placenta and membranes from upward to downward direction.

All CSs were carried out by the same team of study investigators under spinal anesthesia, using a 25-gauge needle to inject $0.5 \mathrm{mg}$ morphine and $12 \mathrm{mg} 0.5 \%$ bupivacaine. The technique of CS was the same in all women through Pfannenstiel incision of the skin. Then, vaginae of all women were cleaned with povidone iodine solution immediately before CS. The suture materials were the same in all cases. All patients received $2 \mathrm{~g}$ of cephradine for perioperative prophylaxis after umbilical cord clamping.

The uterine incision was closed with a continuous two layers of Vicryl 0 . The visceral peritoneum was unsutured while the parietal peritoneum was closed with Vicryl 2-0. The rectus sheath was closed with a continuous single layer of Vicryl 1. Lastly, the skin was closed by subcuticular Vicryl 2-0. All suture materials were developed by Ethicon (Somerville, NJ, USA).

\section{Follow-up}

Postoperative care was the same for both the groups. They received intravenous fluids (ringer lactate and $5 \%$ glucose) at the rate of $100 \mathrm{~mL} / \mathrm{h}$ then oral clear fluids were started 6 hours postoperatively. Urinary Foley catheters were removed at 
12 hours post operation. The duration of hospital stay was calculated from the day of CS until discharge from the hospital. Cases with febrile morbidity, defined as a persistent fever of at least $38^{\circ} \mathrm{C}$ for at least 24 hours after surgery not associated with lower abdominal or pelvic tenderness, were recorded.

All women were asked to attend our outpatient clinic 1 week after CS for the assessment of the skin incision and uterine cavity to exclude wound infection and endometritis. Wound infection was diagnosed if purulent discharge from the incision, swelling, erythema, induration, or wound breakdown was present. Endometritis was diagnosed if there is postoperative fever $\left(>38^{\circ} \mathrm{C}\right.$ after the first postoperative day) with uterine tenderness, foul smelling lochia, and leukocytosis (white cell count $>15,000 / \mathrm{mL}$ ). The second follow-up visit was at 6 weeks postpartum for the initiation of family planning method. Uterine subinvolution was assessed in this visit, defined as delayed or absent involution of the uterus during the postpartum period.

The patients were given a follow-up card to be evaluated 6 months after CS by 3D ultrasonography to check for scar integrity and quality. Scar evaluation was assessed by measuring the scar width, scar depth, thickness of the residual myometrial tissue (RMT), vascularity, and integrity (presence or absence of defects). Cesarean scars were assessed by 3D-TVS using Voluson E8 machine (GE healthcare, USA). All ultrasound examinations were carried out by the same investigator who was an expert level II sonographer. The sonographer was blinded to the allocated group of the patients.

\section{Study outcomes}

The primary outcome of the study was the difference in sonographic parameters of scar integrity between the two groups as evaluated 6 months post operation. The secondary outcomes included the duration of hospital stay, the rate of febrile morbidity, uterine subinvolution, wound infection, and endometritis.

\section{Statistical analysis}

The data were collected and entered into a Microsoft Access database and then analyzed using the Statistical Package for Social Science (version 22; IBM Corporation, Armonk, NY, USA). Quantitative variables were presented in terms of mean and standard deviation. They were compared using Student's $t$-test. Qualitative variables were presented as frequency and percentage. Chi-squared test was used for comparison between groups. For analysis, $P<0.05$ was considered to be significant.

\section{Results}

Four hundred twenty-two women were approached to participate in the study. We excluded 16 cases as they did not meet the inclusion criteria and six women refused to participate in the study. The remaining 400 women were randomized to either of the study groups (200 women in each arm). Fortyone women in the study group and 37 women in the control group were excluded from the final analysis as they were lost to follow-up at 6 months (Figure 1). No statistical significant difference were found regarding the baseline characteristics of both the groups (Table 1).

Table 2 demonstrates the outcomes of the study. In the postpartum period, there was no significant difference regarding the rate of wound infection or endometritis in both the groups ( $P=0.717$ and 0.227 , respectively). The incidence of febrile morbidity was higher in the no cervical dilatation group $(10.5 \%)$ compared to the cervical dilatation group $(5.0 \%)(P=0.045)$. A significant difference was noticed regarding the rate of subinvolution which was higher in no cervical dilatation group $(P=0.012)$. In addition, the duration of hospital stay was significantly higher in the no cervical dilatation group $(P=0.001)$.

The results of ultrasonographic scar assessment were shown in Table 3. Scar width, depth were significantly higher in the cervical dilatation group than in control group ( $P=0.002$ and 0.001 , respectively). Fewer cases with scar defects (niche) were found in the cervical dilatation group than in the control group $(5.03 \%$ vs $11.04 \%$, respectively, $P=0.048$ ) as shown in Figure 2. Even the RMT was thicker in the cervical dilatation group than the control group $(6.5 \pm 1.4$ vs $4.7 \pm 2.3 \mathrm{~mm}$, respectively, $P=0.002$ ) as shown in Figures 3 and 4. Scars in the study group were more vascular than in the control group $(P=0.002)$.

\section{Discussion}

In the present study, we found that mechanical cervical dilatation during elective $\mathrm{CS}$ is associated with reduced rate of febrile morbidity, uterine subinvolution, and duration of hospital stay with no effect on the rates of wound infection and endometritis. Moreover, the scar integrity and vascularity 6 months postpartum was significantly better with cervical dilatation.

The efficacy of mechanical cervical dilatation during elective CS is still debatable. Previous studies conducted to assess the surgical outcomes and postpartum maternal health had equivocal conclusions that dilatation of the cervix is not associated with improved surgical outcomes. ${ }^{6}$ Evidence failed to support the occurrence of infectious morbidity in patients with cervical dilatation during elective $\mathrm{CS}{ }^{6}$ 


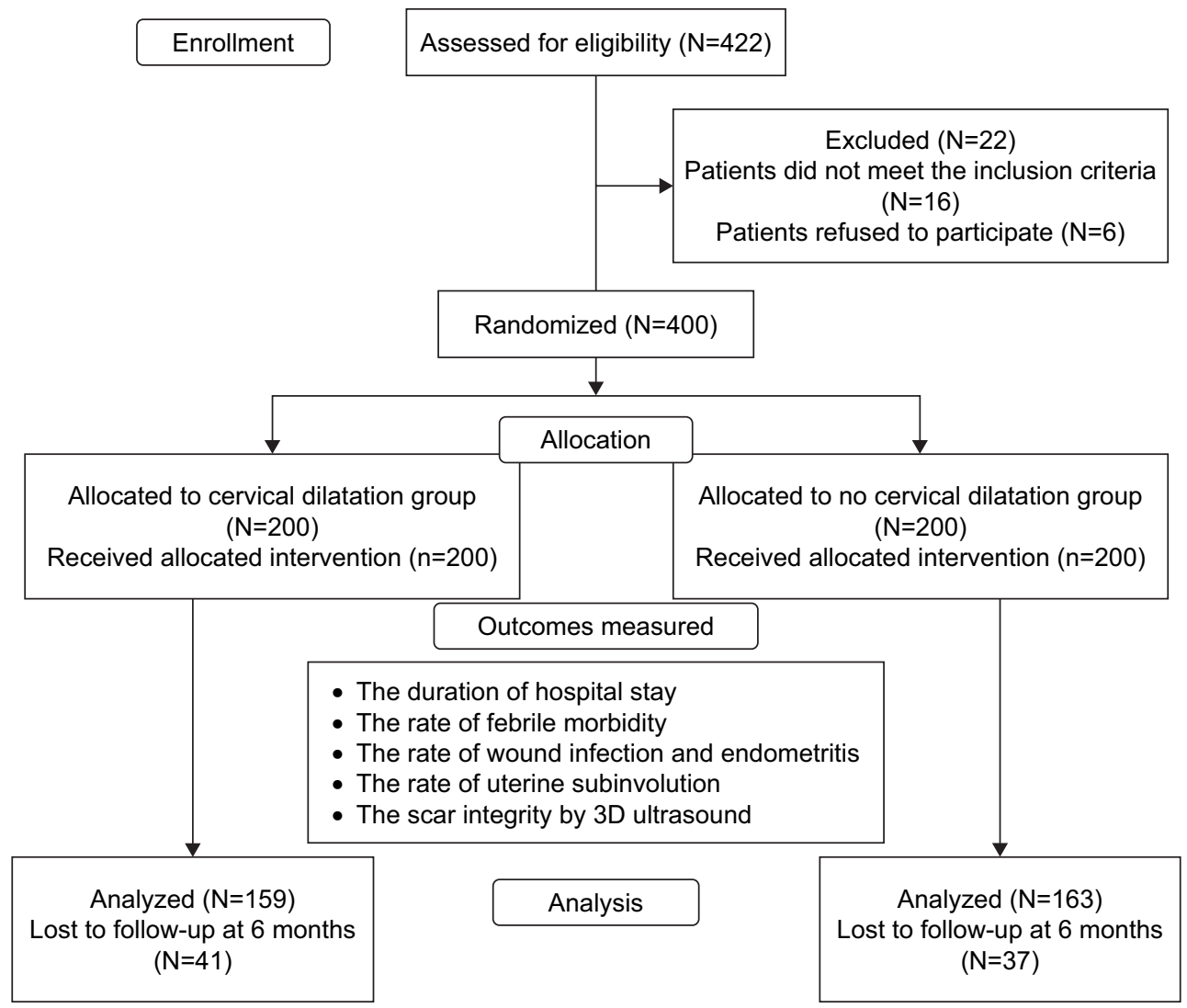

Figure I The study flowchart.

This could be attributed to the difference in primary and secondary outcomes, small sample size, and variable methods of evaluation of the study outcomes.

The rationale to dilate the cervix during elective CS was allowance of more drainage of blood and products of conception through the dilated cervix. Retained blood may distend the LUS with subsequent atony, PPH, and further need for blood transfusion. Moreover, retention of blood

Table I The baseline characteristics of the study participants

\begin{tabular}{l|l|l|l}
\hline Variables & $\begin{array}{l}\text { Cervical } \\
\text { dilatation } \\
(\mathbf{n}=\mathbf{2 0 0})\end{array}$ & $\begin{array}{l}\text { No cervical } \\
\text { dilatation } \\
(\mathbf{n}=\mathbf{2 0 0})\end{array}$ & P-value \\
\hline Age (years) $^{\mathrm{a}}$ & $29.45 \pm 6.58$ & $29.20 \pm 6.30$ & 0.727 \\
Parity $^{\mathrm{a}}$ & $2.60 \pm \mathrm{I} .74$ & $2.48 \pm \mathrm{I} .6 \mathrm{I}$ & $0.52 \mathrm{I}$ \\
Maternal BMI $\left(\mathrm{kg} / \mathrm{m}^{2}\right)^{\mathrm{a}}$ & $25.9 \pm 4.63$ & $26.3 \pm 4.55$ & 0.434 \\
Gestational age $($ weeks) & $38.18 \pm \mathrm{I} .12$ & $38.15 \pm \mathrm{I} . \mathrm{II}$ & 0.809 \\
No of previous CS & & & \\
No CS & $75(37.5)$ & $73(36.5)$ & 0.668 \\
One CS & $82(41.0)$ & $76(38.0)$ & \\
Two CS & $27(13.5)$ & $30(15.0)$ & \\
Three or more CS & $16(8.0)$ & $21(10.5)$ & \\
\hline
\end{tabular}

Notes: a $D$ ata are presented as mean $\pm S D$ and compared using Student's $t$-test. 'Data are presented as frequency (percentage) and compared using chi-squared test. Abbreviations: BMI, body mass index; CS, cesarean section. in the LUS increases postoperative pain and stretches the cesarean scar leading to defective scar integrity that could predispose to scar ectopic pregnancy or uterine rupture in the future pregnancies. ${ }^{15}$ The opposite rationale for cervical dilatation was increasing the risk of contamination of uterine and abdominal wounds with vaginal infections if cervical dilatation was performed. ${ }^{16}$

Regarding infectious morbidity, we found no significant differences regarding endometritis or wound sepsis between the two groups. We speculated that febrile morbidity was

Table 2 The rate of infectious morbidity in both the study groups after $\mathrm{CS}$

\begin{tabular}{l|l|l|l}
\hline Variables & $\begin{array}{l}\text { Cervical } \\
\text { dilatation }\end{array}$ & $\begin{array}{l}\text { No cervical } \\
\text { dilatation }\end{array}$ & P-value \\
\hline Febrile morbidity $^{\mathrm{a}}$ & $10(5.0)$ & $2 \mathrm{I}(10.5)$ & $0.045^{\mathrm{b}}$ \\
\hline Wound infection $^{\mathrm{a}}$ & $\mathrm{II}(5.5)$ & $13(6.5)$ & 0.717 \\
\hline Endometritis $^{\mathrm{a}}$ & $3(1.5)$ & $2(\mathrm{I} .0)$ & 0.227 \\
\hline Uterine subinvolution $^{\mathrm{a}}$ & $2(1.0)$ & $\mathrm{II}(5.5)$ & $0.012^{\mathrm{b}}$ \\
\hline Duration of hospital stay (days) $^{\mathrm{c}}$ & $4.17 \pm \mathrm{I} .10$ & $4.77 \pm \mathrm{I} .17$ & $0.00 \mathrm{I}^{\mathrm{b}}$ \\
\hline
\end{tabular}

Notes: ${ }^{2}$ Data are presented as frequency (percentage) and compared using chi-squared test. ${ }^{b}$ Statistical significant difference. ${ }^{~} D a t a$ are presented as mean $\pm S D$ and compared using Student's t-test.

Abbreviation: CS, cesarean section. 
Table 3 The results of ultrasonographic scar assessment in both the study groups 6 months after CS

\begin{tabular}{|c|c|c|c|}
\hline Variables & $\begin{array}{l}\text { Cervical } \\
\text { dilatation } \\
(n=159)\end{array}$ & $\begin{array}{l}\text { No cervical } \\
\text { dilatation } \\
(n=163)\end{array}$ & $P$-value \\
\hline Scar width $(\mathrm{mm})^{\mathrm{a}}$ & $23.48 \pm 5.70$ & $21.40 \pm 3.88$ & $0.002^{\mathrm{b}}$ \\
\hline Scar depth $(\mathrm{mm})^{\mathrm{a}}$ & $11.58 \pm 0.92$ & $9.88 \pm 0.56$ & $0.000 I^{\mathrm{b}}$ \\
\hline $\begin{array}{l}\text { Scar distance from } \\
\text { internal os }(\mathrm{mm})^{\mathrm{a}}\end{array}$ & $9.5 \pm 1.7$ & $8.8 \pm 1.3$ & $0.000 I^{b}$ \\
\hline Scar defect (niche) ${ }^{c}$ & $8(5.03)$ & $18(11.04)$ & $0.048^{b}$ \\
\hline $\begin{array}{l}\text { Residual MT in niche } \\
\text { cases }(\mathrm{mm})^{\mathrm{a}}\end{array}$ & $6.5 \pm 1.4$ & $4.7 \pm 2.3$ & $0.002^{\mathrm{b}}$ \\
\hline $\begin{array}{l}\text { Scar vascularityc } \\
\text { Hyper-vascular } \\
\text { Hypo-vascular }\end{array}$ & $\begin{array}{l}56(35.22) \\
103(64.78)\end{array}$ & $\begin{array}{l}33(20.25) \\
130(79.75)\end{array}$ & $0.002^{\mathrm{b}}$ \\
\hline
\end{tabular}

Notes: ${ }^{a}$ Data are presented as mean \pm SD and compared using Student's t-test. 'Statistical significant difference. 'Data are presented as frequency (percentage) and compared using chi-squared test.

Abbreviations: MT, myometrial thickness; CS, cesarean section.

higher in the non-dilated cervix group owing to retained blood in the LUS. Our results were similar to most of the previous studies in these outcomes. ${ }^{4,17-22}$

Ahmed et al conducted a clinical trial to evaluate the effect of routine cervical dilatation during elective $\mathrm{CS}$ on maternal morbidity on 131 patients. They found that cervical dilatation did not reduce the risk of postoperative maternal fever or wound infection. ${ }^{5}$ Tosun et al conducted a randomized trial to investigate the necessity of cervical dilation in elective CS on 150 patients. They found similar results as previous studies, but the only difference was that the endometrial thickness was more in non-dilated cervix group than in dilated cervix group $(9.51 \pm 3.35$ vs $6.87 \pm 2.50 \mathrm{~mm})$. They explained that thick endometrial cavity may be due to presence of retained fluid and blood in the uterine cavity, increasing the occurrence of hematometra. ${ }^{17}$ Similar results regarding endometrial thickness were obtained by Sakinci et al. ${ }^{21}$

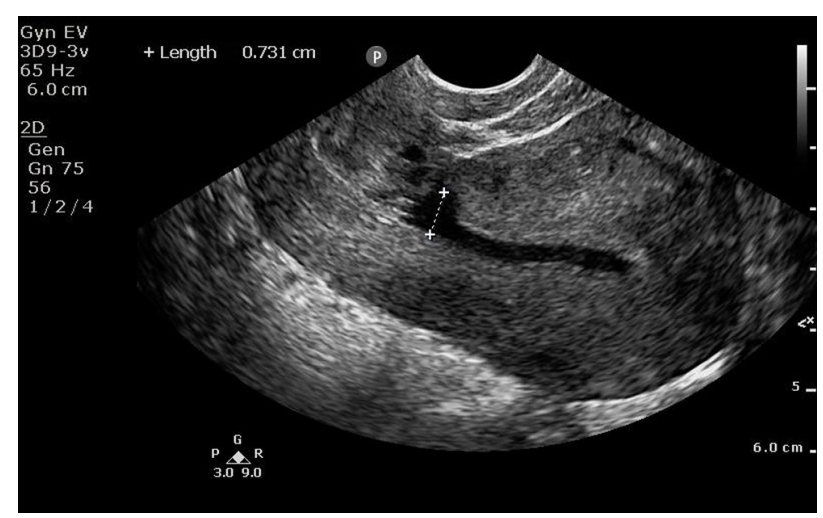

Figure 2 Cesarean scar defect by 2D ultrasound.

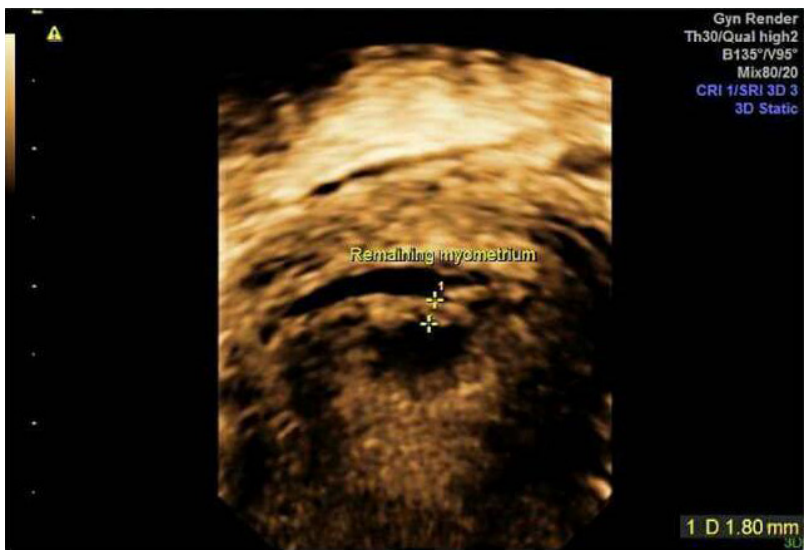

Figure 3 Residual myometrial tissue assessment by 3D ultrasound in no cervical dilatation group.

Recently, Kirscht et al conducted a randomized controlled study (Dondi Trial) on 447 patients to assess the effects of cervical dilatation on postoperative morbidity. They found no significant difference in infectious morbidity between the two groups. The only difference reported was that the retained products of conception were nil in the dilatation group compared to $6.2 \%$ in the no dilatation group $(P<0.001){ }^{20}$

One of the aims of the current study is to assess the effect of cervical dilatation on the scar vascularity and integrity. The scar was assessed after 6 months of CS to allow for complete healing and return of regional anatomy to pre-pregnancy state. One study approved that scar could be assessed readily at 6 weeks. ${ }^{23}$ Other studies have assessed the scar at 3 months or at 6 months to ensure the scar edema has resolved and complete healing had occurred. ${ }^{7,24-26}$

The current study is considered the first one to assess the effect of cervical dilation on the cesarean scar quality and

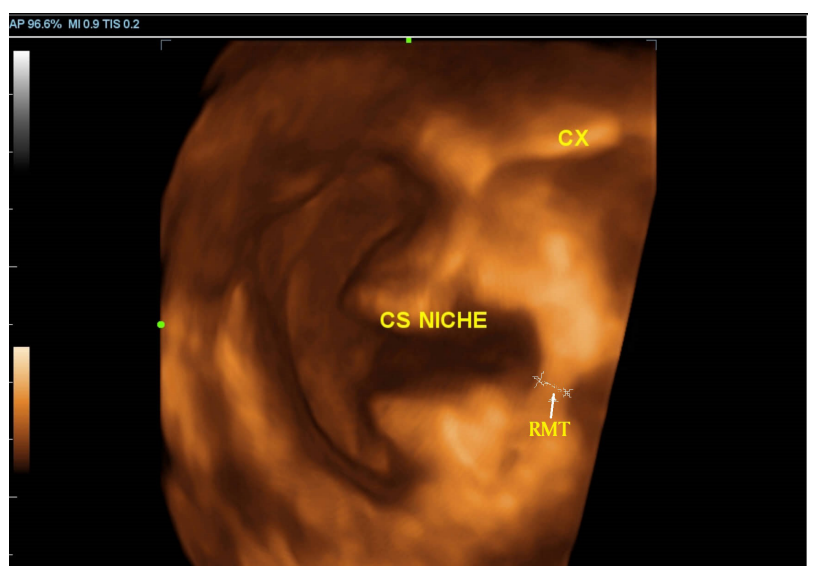

Figure 4 RMT assessment by 3D ultrasound in cervical dilatation group. Abbreviations: CS, cesarean section; RMT, residual myometrial tissue; CX, cervix. 
integrity. Scar width, depth, and location were significantly higher in dilatation group. Moreover, fewer cases of scar defects were noticed in the dilatation group than in no dilatation group (5.03\% vs $11.04 \%$, respectively). The RMT in the scar defect was thicker in the dilatation group $(P=0.002)$. The color Doppler examination revealed more vascularization of scar in the dilatation group $(P=0.002)$. The explanation for these findings may be the stretching of the LUS and distention by retained blood leading to weak scar and poor healing with subsequent more scar defects and thin scars.

The strengths of our study include that it was a randomized clinical trial. In addition, all CSs were carried out by the same team using the same surgical steps and type of anesthesia was standardized. Limitations included the inability to calculate the ideal sample size according to the primary outcome as no previous studies had assessed the scar integrity after cervical dilatation.

\section{Conclusion}

Cervical dilatation during elective CS was safe and not associated with increase in postoperative infectious morbidity regarding endometritis or wound sepsis. Scar evaluation revealed that cervical dilatation yields thick scars with low incidence of scar defects.

\section{Data sharing}

The authors do not intend to share individual de-identified participant data.

\section{Disclosure}

The authors report no conflicts of interest in this work.

\section{References}

1. Betrán AP, Ye J, Moller AB, Zhang J, Gülmezoglu AM, Torloni MR. The increasing trend in Caesarean section rates: global, regional and national estimates: 1990-2014. PLoS One. 2016;11(2):e0148343.

2. Mylonas I, Friese K. Indications for and risks of elective cesarean section. Dtsch Arztebl Int. 2015;112(29-30):489.

3. Dahlke JD, Mendez-Figueroa H, Rouse DJ, Berghella V, Baxter JK, Chauhan SP. Evidence-based surgery for cesarean delivery: an updated systematic review. Am J Obstet Gynecol. 2013;209(4):294-306.

4. Güngördük K, Yildirim G, Ark C. Is routine cervical dilatation necessary during elective caesarean section? A randomised controlled trial. Aust $N$ Z J Obstet Gynaecol. 2009;49(3):263-267.

5. Ahmed B, Abu Nahia F, Abushama M. Routine cervical dilatation during elective cesarean section and its influence on maternal morbidity: a randomized controlled study. $J$ Perinat Med. 2005;33(6):510-513.

6. Liabsuetrakul T, Peeyananjarassri K. Mechanical dilatation of the cervix at non-labour cesarean section for reducing postoperative morbidity. Cochrane Database Syst Rev. 2011;11:CD008019.
7. Naji O, Abdallah Y, Bij de Vaate AJ, et al. Standardized approach for imaging and measuring Cesarean section scars using ultrasonography. Ultrasound Obstet Gynecol. 2012;39(3):252-259.

8. Yazicioglu F, Gökdogan A, Kelekci S, Aygün M, Savan K. Incomplete healing of the uterine incision after caesarean section: is it preventable? Eur J Obstet Gynecol Reprod Biol. 2006;124(1):32-36.

9. Poidevin LO. The value of hysterography in the prediction of cesarean section wound defects. Am J Obstet Gynecol. 1961;81(1):67-71.

10. Burger NF, Darazs B, Boes EG. An echographic evaluation during the early puerperium of the uterine wound after caesarean section. $J$ Clin Ultrasound. 1982;10(6):271-274.

11. Chen HY, Chen SJ, Hsieh FJ. Observation of cesarean section scar by transvaginal ultrasonography. Ultrasound Med Biol. 1990;16(5): 443-447.

12. Jastrow N, Antonelli E, Robyr R, Irion O, Boulvain M. Inter- and intraobserver variability in sonographic measurement of the lower uterine segment after a previous Cesarean section. Ultrasound Obstet Gynecol. 2006;27(4):420-424.

13. Martins WP, Barra DA, Gallarreta FM, Nastri CO, Filho FM. Lower uterine segment thickness measurement in pregnant women with previous Cesarean section: reliability analysis using two- and threedimensional transabdominal and transvaginal ultrasound. Ultrasound Obstet Gynecol. 2009;33(3):301-306.

14. Shehata Dawood A, Dawood AS, Dawood AG, El-Shwaikh SL. A three year retrospective study of Caesarean section rate at Tanta University Hospitals. J Gynecol Obstet. 2017;5(2):25-30.

15. Bollapragada SS, Edozien LC. Apparent absence of lochia after elective caesarean section. J Obstet Gynaecol. 2002;22(5):558.

16. Sherman D, Lurie S, Betzer M, Pinhasi Y, Arieli S, Boldur I. Uterine flora at cesarean and its relationship to postpartum endometritis. Obstet Gynecol. 1999;94(5 Pt 1):787-791.

17. Tosun M, Sakinci M, Çelik H, et al. A randomized controlled study investigating the necessity of routine cervical dilatation during elective cesarean section. Arch Gynecol Obstet. 2011;284(1):85-89.

18. Osemwenkha A, Olagbuji BN, Ezeanochie MC. A comparative study on routine cervical dilatation at elective cesarean section. Afr J Med Health Sci. 2013;12:78-81.

19. Ezegwui HU, Ogbuefi FC. Routine cervical dilatation during elective caesarean section. Should we continue? J Obstet Gynaecol. 2015;35(2): $150-152$.

20. Kirscht J, Weiss C, Nickol J, et al. Dilatation or no dilatation of the cervix during cesarean section (Dondi Trial): a randomized controlled trial. Arch Gynecol Obstet. 2017;295(1):39-43.

21. Sakinci M, Kuru O, Olgan S, et al. Dilatation of the cervix at non-labour caesarean section: Does it improve the patients' perception of pain post-operatively? J Obstet Gynaecol. 2015;35(7):681-684.

22. Koifman A, Harlev A, Sheiner E, Press F, Wiznitzer A. Routine cervical dilatation during elective cesarean delivery - Is it really necessary? J Matern Fetal Neonatal Med. 2009;22(7):608-611.

23. Dosedla E, Calda P. Can the final sonographic assessment of the cesarean section scar be predicted 6 weeks after the operation? Taiwan $J$ Obstet Gynecol. 2016;55(5):718-720.

24. Hamar BD, Saber SB, Cackovic M, et al. Ultrasound evaluation of the uterine scar after cesarean delivery. Obstet Gynecol. 2007;110(4): 808-813.

25. Sevket O, Ates S, Molla T, Ozkal F, Uysal O, Dansuk R. Hydrosonographic assessment of the effects of 2 different suturing techniques on healing of the uterine scar after cesarean delivery. Int J Gynaecol Obstet. 2014;125(3):219-222.

26. Glavind J, Madsen LD, Uldbjerg N, Dueholm M. Ultrasound evaluation of Cesarean scar after single- and double-layer uterotomy closure: a cohort study. Ultrasound Obstet Gynecol. 2013;42(2):207-212. 
International Journal of Women's Health

Dovepress

\section{Publish your work in this journal}

The International Journal of Women's Health is an international, peerreviewed open-access journal publishing original research, reports, editorials, reviews and commentaries on all aspects of women's healthcare including gynecology, obstetrics, and breast cancer. The manuscript management system is completely online and includes Visit http://www.dovepress.com/testimonials.php to read real quotes from published authors.

Submit your manuscript here: http://www.dovepress.com/international-journal-of-womens-health-journal 